\title{
e-Migrinter
}

$5 \mid 2010$

Migrations dans les pays nordiques

\section{Migrations dans les pays nordiques}

Figures, parcours, contexte

\section{Gunhild Odden}

\section{(2) OpenEdition}

\section{Journals}

Édition électronique

URL : https://journals.openedition.org/e-migrinter/1887

DOI : 10.4000/e-migrinter.1887

ISSN : 1961-9685

Éditeur

UMR 7301 - Migrinter

Édition imprimée

Date de publication : 28 avril 2010

Pagination : 2-4

ISSN : 1961-9685

Référence électronique

Gunhild Odden, « Migrations dans les pays nordiques », e-Migrinter [En ligne], 5 | 2010, mis en ligne le 20 avril 2020, consulté le 20 mai 2021. URL : http://journals.openedition.org/e-migrinter/1887 ; DOI : https://doi.org/10.4000/e-migrinter.1887 


\section{ÉDITORIAL}

\section{Migrations dans les pays nordiques : figures, parcours, contexte}

\section{Gunhild Odden}

\section{$\mathbf{H}$}

istoriquement région d'émigration, les pays nordiques accueillent aujourd'hui une importante population migrante aux statuts et origines divers. Demandeurs d'asile, réfugiés statutaires, migrants économiques ou élites migrantes, tous trouveront leur place dans ce dossier qui contient des contributions écrites par des auteurs originaires de différents pays, institutions et disciplines académiques.
Lorsque l'on se réfère aux pays nordiques, expression souvent employée par erreur comme synonyme de pays scandinaves, il convient tout d'abord de préciser de quels pays on parle. Les pays nordiques sont en effet la Suède, la Norvège, la Finlande, le Danemark et l'Islande. Dans cette appellation on peut également ajouter les trois territoires autonomes que sont le Groenland, les îles Féroé et l'archipel de Aland ${ }^{1}$. Les pays scandinaves ne comprennent en revanche que la Norvège, la Suède et le Danemark.

Les migrations dans les différents pays nordiques sont marquées par certaines similitudes. La forte tradition d'accueil des réfugiés et des demandeurs d'asile en constitue une. Dans la première partie de ce dossier, trois textes se penchent sur la population de réfugiés et de demandeurs d'asile.

Pour beaucoup de ces migrants, le choix de se rendre dans les pays nordiques est plus déterminé par des contraintes contextuelles que par un projet clairement défini depuis le pays d'origine. À partir de l'exemple des jeunes afghans à Paris, Jean Michel Centres montre que pour ces migrants, les pays du Nord se présentent comme des pays plus opportuns que la France : tout demandeur d'asile s'y voit proposer un logement et les taux d'acceptation des demandes sont plus élevés. Ainsi, plutôt que de rester en France où ils rencontrent des conditions de vie peu

\footnotetext{
${ }^{1}$ Les deux premiers de ces territoires appartiennent au Danemark, le troisième à la Finlande.
} 
favorables, ou de tenter la traversée de la Manche afin de rejoindre l'Angleterre (une traversée de plus en plus difficile) certains de ces jeunes afghans reformulent leur projet et décident de tenter leur chance dans les pays nordiques, et surtout en Suède et en Norvège.

Le texte de Kamel Doraï sur les Irakiens en Suède, s'appuyant sur un travail de terrain réalisé en Syrie et en Suède, dévoile lui aussi cette migration par étapes et la capacité des migrants à adapter des stratégies leur permettant de faire face aux difficultés rencontrées au fur et à mesure du parcours migratoire. $\mathrm{Si}$ pour certains Irakiens, la Syrie se présente comme un premier pays d'installation, cette dernière reste précaire. En mobilisant des réseaux familiaux, certains parviennent à poursuivre leur parcours vers la Suède, l'un des premiers pays d'accueil des réfugiés irakiens hors du Moyen-Orient. Comme le montre l'auteur, la migration irakienne vers la Suède s'inscrit dans une temporalité qui a débuté dès les années 1980 et peut actuellement s'expliquer par divers facteurs tels que la volonté d'échapper aux violences et aux difficultés économiques, mais aussi le regroupement familial.

Après deux papiers où les parcours des réfugiés et des demandeurs d'asile sont centraux, Ane Sætha propose un article à partir d'une étude socio-anthropologique réalisée dans une école primaire multiculturelle norvégienne, située en milieu rural et accueillant plusieurs enfants issus $\mathrm{du}$ centre local d'hébergement des demandeurs d'asile. En discutant des termes tels que la langue, l'intégration, la similarité (« likeness») ou l'appartenance, Sætha interroge le rôle des compétences communicatives dans le processus d'intégration des enfants migrants. L'article s'inscrit plus largement dans le débat du rôle de la décentralisation - ou de la «ghettoïsation" - de l'immigration en Norvège.
La deuxième partie du dossier est composée de trois textes où l'aspect économique des migrations dans les pays nordiques est mis en avant. Unnur Dís Skaptadóttir questionne les activités transnationales et le processus d'intégration des Philippins en Islande. Elle s'intéresse plus particulièrement aux expériences liées à la vie familiale et au travail et montre qu'une participation économique et sociale dans la société islandaise n'exclut pas l'existence de liens transnationaux et vice-versa.

Anna-Kaisa Ranta retrace d'abord l'histoire migratoire finlandaise. Ayant longtemps associé l'immigration aux réfugiés et aux demandeurs d'asile, ce n'est que très récemment que la Finlande se définit comme un pays d'accueil pour travailleurs étrangers. Dans un deuxième temps, elle développe le cas de l'histoire migratoire africaine et évoque plus singulièrement l'émergence récente de commerces tenus par la population africaine dans un quartier de tradition ouvrière à Helsinki.

Dans un dernier texte, Kaisu Koskela identifie les migrants qualifiés (skilled migrant) comme un objet de recherche émergent en Finlande. Après avoir discuté des différents termes utilisés dans la littérature pour désigner ces migrants, elle nous présente un bilan des études déjà réalisées sur le sujet en Finlande. Ces dernières montrent que ces migrants se sentent peu attachés à la société finlandaise, un fait que l'auteure associe aux politiques finlandaises qui considèrent cette migration comme temporaire. Élaborer une politique d'intégration destinée aux migrants qualifiés en Finlande n'a donc pas été jugé nécessaire.

Ce cinquième numéro de e-migrinter contient également les rubriques habituelles de Vie du Laboratoire et Notes de lectures. Dans cette dernière rubrique, on souligne tout particulièrement la note rédigée par Marie Chabrol. À partir de l'œuvre du romancier 
suédois Henning Mankel, elle démontre comment le roman policier peut faire figure de miroir des nouvelles migrations à l'œuvre dans la société suédoise.

Avant de conclure cette note introductive, je tiens à remercier mes collègues du comité éditorial pour m'avoir donné l'opportunité de réaliser ce dossier sur les migrations dans les pays nordiques, encore peu connues en France. En espérant que cette initiative contribuera à susciter un intérêt plus important pour les dynamiques migratoires actuellement en cours dans cette partie de l'Europe.

Gunhild Odden Doctorante à MIGRINTER Chercheure à SIK ${ }^{2}$, Norvège gunhild.odden@sik.no

2 Senter for interkulturell kommunikasjon (Centre pour la communication interculturelle), Stavanger. 